\title{
Uber và Grab bổ sung một luận điểm mới vào lý thuyết kinh tế học chính trị và chính sách kinh tế
}

\author{
Vũ Cao Đàm* \\ Viện Chính sách và Quản lý, Trương Đại học Khoa học Xã hội và Nhân văn, \\ 336 Nguyễn Trãi, Thanh Xuân, Hà Nội, Việt Nam \\ Nhận ngày 06 tháng 8 năm 2017 \\ Chỉnh sửa ngày 11 tháng 9 năm 2017; Chấp nhận đăng ngày 28 tháng 9 năm 2017
}

\begin{abstract}
Tóm tắt: Sự xuất hiện Uber và Grab không đơn giản là sự xuất hiện một loại dịch vụ mới, thuận tiện cho dân chúng, mà đang đụng đến những vấn đề lý thuyết về triết học, kinh tế học chính trị và chính sách quản lý hiện hữu.

Đó là sự xuất hiện những hãng taxi khổng lồ, không sử hữu bất kỳ một cái taxi nào. Nó gợi ý mọi người liên tưởng đến tư tưởng của cuốn sách Powershift của Alvin Toffler: Quyền lực đang chuyển dịch từ quyền tực tài chính sang quyền lực thong tin.

Tì khóa: Uber và Grab, Dịch vụ, Vật chất, Ý thức, Thông tin, Tư liệu sản xuất, Sở hữu, Lý thuyết, Chính sách.
\end{abstract}

\section{Dẫn nhập}

Năm 1990, sau "Future shock" (1970) và "The Third Wave" (1980), Alvin Toffler cho ra mắt cuốn sách đặc sắc "Powershift". Bản dịch tiếng Việt đặt tền cuốn sách là "Thăng trầm quyền lực", nhưng thực ra cuốn sách không nói về sự thăng trầm của quyền lực, mà nói về sự chuyển dịch của quyền lực, đúng như tên gọi tiếng Anh "Power-shift". - Ở đây, Toffler bàn về sự chuyển dịch từ quyền lực tài chính sang quyền lực thông tin, bản chất sự chuyển dịch về quyền lực đang diễn ra từng ngày trong thế giới đương đại. Nó được thể hiện ngày càng rõ nét từ khi bắt đầu cuộc Cách mạng Công nghiệp Thứ Tư.

\footnotetext{
*ĐT.: 84-966628704.

Email: damvc@vnu.edu.vn

https://doi.org/10.25073/2588-1116/vnupam.4110
}

Sau hơn hai thập niên, từ khi cuốn sách Powershift ra mắt công chúng đến nay, trên đường phố Việt Nam xuất hiện một hình thức kinh doanh mới, Uber và Grab, đang làm chấn động giới kinh doanh và giới quản lý và dẫn đến đau đầu các nhà hoạch định chính sách.

Đây là những hãng taxi khổng lồ, với quyền lực kinh doanh vượt mọi hãng taxi truyền thống, mà không sở hữu bất kỳ một cái taxi nào xét trên giác độ là một tư liệu sản xuất. Điều này trái với luận điểm của lý thuyết kinh tế học chính trị kinh điển: Quyền lực thuộc về những kẻ sở hữu tư liệu sản xuất.

Luận điểm của Alvin Toffler trong Powershift đang được thể hiện sinh động ngay trên đường phố Hà Nội, các thành phố lớn khác của Việt Nam và ở nước ngoài, dẫn đến những phản ứng xã hội khác nhau và vô cùng thú vị.

Xét cho cùng, Uber và Grab không chỉ là một giải pháp công nghệ mới, mà, hơn thế nữa, 
còn là một sự kiện xã hội và một hiện tượng kinh tế hết sức mới mẻ, chúng ta có thể xem đó chính là một biểu hiện thực tế của cuộc Cách mạng Công nghiệp thứ Tư, đáng bàn cả trên phương diện lý thuyết và thực tiễn.

\section{Xung đột xã hội tất yếu}

Trong trang "Nhịp sống số" có bài "Uber và Grab Taxi bị kiện tại Hà Nội" [1] cho chúng ta biết một số sự kiện thú vị. Tiếp đó chúng ta được biết các hãng taxi ở thành phố Hồ Chí Minh cũng lên tiếng khởi kiện Uber và Grab. Đà Nẵng và một số nơi trên thế giới còn cấm Uber và Grab hoạt động.

Trong các sự kiện vừa dẫn, các hãng taxi truyền thống cho rằng Uber và Grab đang cạnh tranh không lành mạnh, gây bất cập về an toàn giao thông, quản lý giá cước vận tải, chất lượng dịch vụ. Các nhà quản lý giao thông cũng lên án Uber và Grab đã không được đặt trong hệ thống quản lý truyền thống.

Qua các sự kiện, chúng ta được biết, Uber và Grab bị lên án sử dụng taxi không biển hiệu, không logo, không mào, trái với quy định về taxi công cộng, gây khó khăn cho cơ quan quản lý khi điều hành giao thông.

Uber và Grab cũng bị lên án về việc tự đặt giá vận chuyển, không phù hợp với Luật giá hiện hành, không đảm bảo quyền lợi cho khách hàng (!), gây xáo trộn thị trường taxi.

Uber và Grab cũng bị lên án, vì chưa có chế tài kiểm soát về nghiệp vụ của lái xe và niên hạn sử dụng phương tiện, không gắn thiết bị giám sát hành trình, không chịu trách nhiệm khi gặp rủi ro, không đóng bảo hiểm y tế, bảo hiểm xã hội cho lái xe,.. Dư luận cho rằng đó là những bất cập khó có thể chấp nhận".

Theo Điều 67 Luật Giao thông đường bộ và Nghị định 86/2014/NĐ-CP ngày 10/9/2014 của Chính phủ về điều kiện kinh doanh vận tải bằng ô tô thì kinh doanh taxi là một loại kinh doanh có điều kiện, đơn vị kinh doanh phải đáp ứng những điều kiện nhất định như đăng ký kinh doanh, bảo đảm số lượng, phẩm chất và niên hạn sử dụng phương tiện phù hợp với loại hình kinh doanh; xe phải gắn thiết bị giám sát hành trình, lắp đặt bảng hiệu, logo, đồng hồ tính cước.

Các nhà quản lý đòi hỏi, nếu Grab hay Uber muốn tham gia thị trường cung cấp dịch vụ taxi ở Việt Nam thì họ chỉ có thể lựa chọn hoặc hình thức lập doanh nghiệp taxi theo đúng quy định của pháp luật, hoặc ký hợp đồng cung cấp giải pháp công nghệ mới cho các doanh nghiệp taxi hiện có,..

Thậm chí, các nhà quản lý cho rằng, Uber và Grab không phải là đơn vị thuộc loại hình kinh doanh taxi như quy định của Luật Giao thông đường bộ và Nghị định 86 . Và vì vậy, cả Uber, Grab đều vi phạm pháp luật, phải bị xử lý theo pháp luật kinh doanh taxi hiện hành.

Qua các thông tin trên, chúng ta thấy, xung đột giữa Uber và Grab với các hãng taxi truyền thống và với hệ thống quản lý vận tải là rất gay gắt. Đó chính là xung đột giữa một hình thức kinh doanh mới, với nếp kinh doanh và quản lý kinh doanh truyền thống.

Hình thức kinh doanh mới này không phải ngẫu nhiên được sinh ra. Nó chính là biểu hiện những tương tác trong "Cyber-Physical System”, một sản phẩm rất đặc trưng của Cách mạng Công nghiệp Thứ Tư.

\section{Những dị lý buộc tư duy lại về lý thuyết}

Tuy nhiên, đây không đơn thuần là chúng ta đang chứng kiến sự chuyển đổi của xã hội trước các thành tựu mới của cuộc Cách mạng Công nghiệp Thứ Tư, mà trên thực tế, chúng ta đang chứng kiến một cuộc chuyển giao quyền lực, từ quyền lực tài chính sang quyền lực thông tin.

Chúng ta đã rất quen biết một luận điểm trong các bài giảng về kinh tế học chính trị kinh điển: Quyền lực thuộc về kẻ sở hữu tư liệu sản xuất. Chúng ta cũng đã quá quen thuộc với đặc trưng vật chất của tư liệu sản xuất.

Đến khi xuất hiện Uber và Grab thì luận điểm này không còn đứng vững nữa, và có lẽ phải được hiệu chỉnh: Quyền lực thuộc về kẻ sở 
hữu thông tin. Đến đây, chúng ta có thể nghe những lập luận ngụy biện rằng thông tin cũng là vật chất.

Vào thập niên 1950, sau khi xuất hiện cuốn sách Lý thuyết thông tin của Claude E. Shannon (1948), trong đó, tác giả đã đưa ra định nghĩa khái niệm thông tin như chúng ta hiểu ngày nay, giới nghiên cứu trên thế giới đã nảy ra những cuộc tranh luận thú vị, về luận điểm thông tin là "vật chất" hay "ý thức", xét theo tiếp cận triết học; cũng như vậy, thông tin là "trường" hay là "chất" xét theo tiếp cận vật lý học.

Trong phạm vi liên quan chủ đề của bài viết này, chúng tôi giới hạn xem xét thông tin từ tiếp cận triết học.

Đương nhiên, vật mang thông tin chắc chắn là vật chất, song, bản thân thông là vật chất hay ý thức lại là vấn đề không dễ đi đến nhất trí.

Giới nghiên cứu lúng túng, không thể xem thông tin là ý thức, vì một thông tin, chẳng hạn, ngoài phố đang bán ma túy giá rẻ, luôn dẫn đến dăm bảy ý thức khác nhau: anh nghiện nảy ý thức mua mấy tép về xài lai rai; con buôn có ý thức mua mươi lố về bán kiếm lời; anh cảnh sát nảy ý thức ra tóm gọn cả bọn nghiện lẫn con buôn; nhà nghiên cứu có ý thức phanh phui sự kiện này để phân tích, v.v...

Họ cũng lúng túng, không thể xếp thông tin vào vật chất, vì thông tin không có thuộc tính nào của vật chất, xét cả trên phương diện vật lý học, hóa học, sinh học, hoặc triết học.

Và giới nghiên cứu đành thở dài: "Thông tin không phải vật chất, thông tin cũng chẳng phải ý thức, mà thông tin là ... thông tin", và điều này kéo theo một hệ lụy, là dẫn tới sự khủng hoảng các phạm trù cơ bản của triết học: Ngoài hai phạm trù cơ bản, là "Vật chất" và "Ý thức", có lẽ phải xem xét một phạm trù thứ ba: Đó là "Thông tin", và đi xa hơn nữa, ngoài hai trường phái "Duy vật" và "Duy tâm", phải chăng sẽ xuất hiện thêm một trường phái mới: "Duy tin" (?!).

Cuối thập niên 1990 ở Nga xuất hiện một cuốn sách rất thú vị, được tác giả người $\mathrm{Nga}$, Lixin A.I. (Лисин А. И.), đặt tên tiếng Nga là
“Информацилогия” хеm xét hoạt động của vũ trụ này từ góc nhìn của quá trình trao đổi thông tin ${ }^{1}$, bất kể đó là sự trao đổi vật chất hay trao đổi ý thức.

Tuy nhiên, vấn đề không dừng ở đây, mà còn bị đẩy xa hơn nữa. Đó là luận điểm của Toffler trong Powershift: Quyền lực trong xã hội đã tuột tay khỏi các chủ nhân của tư liệu sản xuất. Với sự tấn công của quyền lực thông tin, thì các doanh nghiệp với hàng núi tư liệu sản xuất khổng lồ hoàn toàn có nguy cơ trở thành nhà chứa đống rác thải (!).

Đúng vậy, chúng ta đang chứng kiến: Với sự phát triển của các "hãng taxi" Uber và Grab, trong tay không có một cái taxi nào, cuộc sống của hàng ngàn người lao động của các hãng taxi truyền thống đang bị đe dọa nghiêm trọng, thậm chí, nếu không có giải pháp ứng phó kịp thời, có thể biến các taxi của các hãng truyền thống thành một đống sắt vô dụng.

Thực tế này đặt ra một vấn đề hết sức thú vị về mặt lý luận, cả trong triết học, cả trong kinh tế học chính trị.

\section{4. Đòi hỏi điều chỉnh trong chính sách}

Qua các thông tin trên mạng, chúng ta biết được các cơ quan quản lý đang đau đầu trong việc điều chỉnh chính sách quản lý taxi.

Cũng qua các thông tin trên mạng, chúng ta hiểu, các nhà hoạch định chính sách hiện còn lúng túng, chưa tìm ra được giải pháp khả dĩ, vừa không cản trở xu thế tiến bộ công nghệ, vừa tạo được sự kết hợp hài hòa giữa tiến bộ công nghệ với hoạt động truyền thống.

Đương nhiên, không thể đưa ra những chính sách nhằm bóp chết xu thế tiến bộ công nghệ. Uber và Grab là những tiến bộ công nghệ. Nó đang mở ra cho người dân những thuận lợi mới,

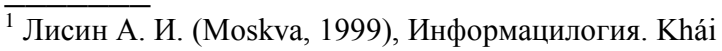
niệm "Информацилогия" được chính Lixin phiên âm tiếng Anh là Informationlogy. Khái niệm này rất khó chuyển ngữ sang tiếng Việt. Rõ ràng không thể dịch là "Thông tin học", vì đã tồn tại một lĩnh vực khoa học mang tên là "Theory of Information".
} 
chưa từng tồn tại. Không thể vì bảo vệ những non kém của taxi truyền thống mà tìm cách cản trở sự phát triển Uber và Grab.

Và cũng đương nhiên, không thể chấp nhận sự tiến bộ công nghệ để làm chết một cách tức tưởi các ngành nghề truyền thống.

Đây là vấn đề của các nhà hoạch định chính sách.

Chúng ta nhớ lại thập niên 1980, sau khi chế độ "Khoán" trong nông nghiệp ra đời, hàng loạt trạm xay sát cơ giới xuất hiện, đã bóp chết nghề thủ công truyền thống về đóng cối xay tre hoặc cối xay đất. Đến nay, mới hơn ba thập niên, mà tìm một thợ đóng cối xay thủ công để đưa vào nhà bảo tàng mà tìm không ra.

Vấn đề đặt trước các nhà hoạch định chính sách, là phải đưa ra các chính sách cập nhật trình độ công nghệ cao trong dịch vụ và trong quản lý dịch vụ.

Tác giả bài viết này không có nhiệm vụ đề xuất giải pháp chính sách, mà chỉ nêu quan điểm về sự cần thiết phải cập nhật những vấn đề lý luận của thời đại, và hơn nữa, bàn về sự cần thiết phải điều chỉnh chính sách thúc đẩy tiến bộ công nghệ để giảm thiểu xung đột xã hội giữa cái mới và cái cũ, và hội nhập với thế giới trong Cuộc Cách mạng Công nghiệp Thứ Tư.

Vấn đề là, phải sắm cái áo khoác mới trong các giải pháp quản lý cho một cơ thể xã hội đang lớn nhanh trong cuộc Cách mạng Công nghiệp Thứ Tư.

\section{Tín hiệu chuyển mình của xã hội}

Thông điệp tác giả mong muốn gửi gắm trong bài viết này, khởi phát từ một sự kiện rất nhỏ, là Uber và Grab, xuất hiện trong cuộc Cách mạng Công nghiệp Thứ Tư đang gây những xáo trộn xã hội một cách bất ngờ và thú vị. Đó là những xung đột xã hội tất yếu giữa cái mới đang lên và cái cũ chưa đển lúc lụi tàn.

Điều thú vị, là trong khi bài viết này đang trên đường hoàn tất, thì tác giả đọc được bài viết của các tác giả Đào Thanh Trường và Nguyễn Thị Quỳnh Anh bàn về việc sử dụng mô hình Uber trong chính sách thu hút nhân lực $\mathrm{KH} \& \mathrm{CN}$ [2]. Từ đây cho thấy một gợi ý, không chỉ tồn tại thực tế Uber và Grab trong lĩnh vực dịch vụ taxi, mà đây là một gợi ý nhân rộng mô hình Uber và Grab trong hàng loạt hoạt động xã hội khác.

Trong mô hình Uber và Grab, nếu quan sát kỹ, chúng ta nhận ra một hệ thống cam kết rất đặc biệt trong khuôn khổ của một phần mềm ứng dụng được gọi là "Blockchain". Đó là một cơ sở dữ liệu phân cấp thông tin, được liên kết với nhau và mở rộng theo thời gian. Blockchain tạo ra một cơ chế đồng thuận phi tập trung (decentralized consensus), thực hiện những cam kết trong khuôn khổ một loại hợp đồng thông minh (smart contracts), dựa trên một hệ thống tính toán tin cậy (trust computing). Từ đây hình thành sự minh bạch trong giao dịch, loại trừ sự can thiệp của các hành vi đạo đức hoặc phi đạo đức của các thành viên tham gia.

Với sự tồn tại hệ thống "Blockchain", mô hình Uber và Grab mở ra một tín hiệu chuyển mình của xã hội, đáng để chúng ta suy nghĩ từ giác độ chính sách về việc hình thành hệ thống quản lý các hoạt động xã hội, và trực tiếp là quản lý các hoạt động kinh doanh thông qua "Blockchain"

\section{Kết luận}

Tác giả bài viết này chợt nhớ đã đọc ở đâu đó, Maxim Gorky có một câu nói thật dí dỏm, rất hợp trong trường hợp này: "Trời đã sáng bảnh, nhưng các cụ lớn không tin. Các cụ gọi bọn kẻ hầu phán bảo: Các người hãy mở Bách khoa Toàn thư tra xem có đúng thật như thế không?".

Chúng ta hy vọng sẽ không trở thành các "Cụ lớn” của Maxim Gorky, sai bọn kẻ hầu tra Bách khoa Toàn thư, xem có thật đang tồn tại hiệu ứng Uber và Grab, tuy mới hình thành không lâu, nhưng đang rung chuyển cả một hệ thống lý thuyết kéo dài từ giữa thế kỷ 19 đến nay, và hệ thống quản lý truyền thống ngay trong đời sống thường nhật của chúng ta. 


\section{Tài liệu tham khảo}

[1] http://nss.vn/ca21-n30055-uber-va-grab-taxi-bi-kientai-ha-noi.htm
[2] Đào Thanh Trường và Nguyễn Thị Quỳnh Anh, "UBER" nhân lực R\&D - Một tiếp cận trong thu hút và sử dụng nhân lực hiện nay, Tạp chí Khoa học, Nghiên cứu Chính sách và Quản lý, Vol. 99, No. 1, 2017.

\title{
Uber and Grab Add A New Thesis to the Theory of Political Economics and Economic Policy
}

\author{
Vu Cao Dam \\ Institute of Policy and Management, VNU University of Social Sciences and Humanities, \\ 336 Nguyen Trai, Thanh Xuan, Hanoi, Vietnam
}

\begin{abstract}
The appearance of Uber and Grab has not been simply a new service of taxi, favourable for the people, however, makes a strong impact to the theorical basis of phisolophy, political economics and nowadays policy.

It is very interesting that Uber and Grab are the big taxi companies, which have not owned any taxi. That fact reminds us of the idea of the book of Alvin Toffler "Powershift": The power is now in shifting: From financial power to the information one.

Keywords: Uber and Grab, Service, Matter, Cognition, Information, Means of Production, Theory, Policy.
\end{abstract}

